\title{
Investigation on the Role of Steel Slag Powder in Blended Cement Based on Quartz Powder as Reference
}

\author{
Wei He $\mathbb{D}^{1}{ }^{1}$ Jihui Zhao $\mathbb{D},{ }^{2,3}$ and Gangqiang Yang ${ }^{2}$ \\ ${ }^{1}$ School of Civil and Transportation Engineering, Beijing University of Civil Engineering and Architecture, Beijing 100044, China \\ ${ }^{2}$ School of Civil Engineering, Sun Yat-sen University, Guangzhou 510275, China \\ ${ }^{3}$ Southern Marine Science and Engineering Guangdong Laboratory, Zhuhai 519082, China
}

Correspondence should be addressed to Jihui Zhao; zhaojihui324@163.com

Received 17 February 2021; Revised 21 April 2021; Accepted 12 June 2021; Published 29 June 2021

Academic Editor: Yushi Liu

Copyright $\left({ }_{0} 2021\right.$ Wei He et al. This is an open access article distributed under the Creative Commons Attribution License, which permits unrestricted use, distribution, and reproduction in any medium, provided the original work is properly cited.

\begin{abstract}
To clarify the role of steel slag powder in blended cement, steel slag powders with different amounts and particle sizes were mixed into blended cement and the inert quartz powder was selected as the reference. The influences of steel slag powder with different amounts and particle sizes on the hydration and hardening properties of blended cement were studied from hydration heat, nonevaporable water content, porosity, hydration products, and strength. The results show that the influence coefficient of nonevaporable water content $\left(\phi_{\mathrm{Wn}}\right)$ of blended cement paste is in an exponential relationship with the amount of steel slag powder. Moreover, at a dosage of $30 \%, \Phi_{\mathrm{Wn}}$ of blended cement gradually decreases with the increase of steel slag particle size. Both the early and late compressive strengths of blended cement are in a binomial relationship with the amount of steel slag powder. The influence coefficient of steel slag powder on the compressive strength of blended cement is negative at the age of 3 days, whereas it is positive at the age of 28 days. The chemical filling effect of $30 \%$ steel slag powder with different particle sizes in the blended cement paste is very small, only $1.13 \%-5.06 \%$. The hydration products of blended cement containing steel slag are mainly amorphous C-S-H gels and platy $\mathrm{Ca}(\mathrm{OH})_{2}$, and their density are consistent with the law of their porosity.
\end{abstract}

\section{Introduction}

It is well known that cement-based material is a nonhomogeneous and multiphase porous material [1-3]. The pore structure (including porosity and pore size distribution) and hydration reaction characteristics (including hydration degree, hydration product type, and quantity) are two key factors that affect the overall performance of cement-based materials [4-7]. Except for cement clinker, modern cementbased materials usually contain supplementary cementitious materials, such as slag and fly ash [8-10]. According to a lot of scholars' research, the influences of supplementary cementitious materials components on the properties of cement-based composites include two aspects: chemical action (i.e., the hydration reaction role) and the physical action (i.e., the physical filling role) [11-13]. The chemical action is not related to only the intrinsic activity of the supplementary cementitious component itself but also its interaction with cement clinker, while the physical action is mainly related to the filling role of the supplementary cementitious component on the system and effect on the pore structure [14-18]. There is a great distinction between the different supplementary cementitious components due to chemical composition, activity, and hydration reaction mechanism, so the hydration and hardening performance of cement-based composites containing different supplementary cementitious materials also greatly differ [19-21]. Therefore, it is necessary to reveal the chemical and physical effects of different supplementary cementitious components on cement-based composites, especially blended cement.

Steel slag is the main industrial waste produced in smelting steel. In China, the basic oxygen converter steel slag is the major kind of steel slag because the main smelting method is dominated by the converter steelmaking. The basic oxygen converter steel slag (hereafter called steel slag in this paper) is rich in silicate minerals, such as dicalcium silicate $\left(\mathrm{C}_{2} \mathrm{~S}\right)$ and tricalcium silicate $\left(\mathrm{C}_{3} \mathrm{~S}\right)$, similar to the mineral components of cement clinker, and it possesses a 
certain hydration activity and cementitious materials after grinding [22-24]. Therefore, it has great potential as supplementary cementitious materials (or called mineral admixture). Meanwhile, the application of steel slag in cement and concrete is also an important way of steel slag resource utilization [25-28]. However, the hydration activity and hydration rate of the steel slag powder are much lower than those of the cement. In the blended cement, the cement clinker firstly starts hydration and hardening reaction, resulting in the formation of the system framework by the hydration products $[25,29,30]$. The effect of steel slag as a supplementary cementitious component on the hydration and hardening of blended cement includes two aspects, i.e., the filling role and the hydration effect. The former leads to the change of pore structure, whereas the latter is reflected in the change of hydration degree of composite cementitious materials. However, most of the current studies in literature focus on the mechanical properties and application effects of steel slag powder in cement and concrete, less paying attention to directly reveal the physical effect (namely, filling role) and chemical effect (namely, hydration role) of steel slag powder with different particle sizes or additional amounts in blend cement. In order to better use the steel slag powder as supplementary cementitious material, it is necessary to reveal the role of the steel slag powder with different amounts or particle sizes in blended cement so as to guide the blended cement containing the steel slag powder to obtain good comprehensive performance.

In this article, steel slag powders with different particle sizes were prepared and mixed into blended cement. The influences of steel slag powder with different amounts or particle sizes on the hydration and hardening properties of blended cement were studied from hydration heat, nonevaporable water content, porosity, hydration products, and strength. Meanwhile, the inert quartz powder, whose particle size distribution is similar to that of the steel slag powder, was also selected as the reference so as to initially reveal the role or contribution of steel slag powder in the hydration and hardening of blended cement. The results of this study also guide how to select or determine the best particle size or addition amounts of steel slag powder in blended cement, which is also meaningful or valuable for the efficient application of steel slag powder building materials.

\section{Materials and Methods}

2.1. Materials. Steel slag used is the converter steel slag after heat-stewing process treatment, which was provided from Laiwu steel company of Shandong province in China. The quartz used is the natural quartz sand with the content of silicon dioxide not less than $95 \%$. The chemical composition and mineral composition, which were determined by X-ray fluorescence (XRF) and X-ray diffraction (XRD) analysis, respectively, are shown in Table 1 and Figure 1.

Steel slag powder and quartz powder with different particle sizes were prepared using a laboratory ball mill under different grinding times. Then, four types of steel slag powders with median diameter in the range of $10 \sim 15 \mu \mathrm{m}$ (denoted by $R 1$ ), 15 20 $\mu \mathrm{m}$ (denoted by $R 2$ ), $20 \sim 30 \mu \mathrm{m}$ (denoted by $R 3$ ), and $60 \sim 70 \mu \mathrm{m}$ (denoted by $R 4$ ) were selected, respectively. Meanwhile, four kinds of quartz powders, whose particle sizes are similar to those of the steel slag powders, were selected as the reference. The median diameters and particle size distribution of powders selected are shown in Table 2 and Figure 2, respectively.

The cement used was prepared using a laboratory ball mill according to the ratio of $95 \%$ clinker with $5 \%$ gypsum. The sieving residue of $80 \mu \mathrm{m}$ is $4.4 \%$, with a specific surface area of $402 \mathrm{~m}^{2} / \mathrm{kg}$ and a median diameter of $20.91 \mu \mathrm{m}$. The chemical composition of cement is also shown in Table 1.

2.2. Mix Design. The mixture proportions shown in Table 3 were designed for the research of the influence of different percentages of steel slag on the hydration and hardening of blended cement. Meanwhile, the influences of steel slag powder with different particle sizes on the properties of the blended cement were studied using the mixture proportions, as shown in Table 4.

\subsection{Testing Methods}

(1) The hydration heat of blended cement paste containing steel slag powder was measured using a TAM Air isothermal calorimeter from TA instruments. The testing was performed at $25^{\circ} \mathrm{C}$, within $96 \mathrm{~h}$, and the water-to-binder ratio of paste is 0.5 .

(2) The blended cement pastes with the water-to-binder ratio of 0.35 were prepared for the determination of nonevaporable water content, morphology, and pore structure of hardened blended cement paste. When the paste specimens were cured at a temperature of about $20 \pm 1^{\circ} \mathrm{C}$ and $>95 \%$ relative humidity to testing ages, the middle portions of specimens were obtained, broken, and soaked in absolute ethanol to stop hydration. Then, the sample is dried at $105^{\circ} \mathrm{C}$ for at least $24 \mathrm{~h}$ so that it reaches a constant weight. Next, the test methods of nonevaporated water content and porosity are as follows:

(a) Before testing the nonevaporable water content, the dried specimens need to be ground into a fine powder (less than $80 \mu \mathrm{m}$ ). Then, the nonevaporable water content was determined as the difference in mass between the specimen heated at $105^{\circ} \mathrm{C}$ and $1000^{\circ} \mathrm{C}$ normalized by the mass after heating at $105^{\circ} \mathrm{C}$ and correcting for the loss on ignition of the unhydrated specimen [31]. The calculation formula is as follows:

$$
W_{n}=\frac{W_{1}-W_{2}}{W_{1}\left(1-L_{S S C}\right)}-\frac{L_{s s c}}{1-L_{s s c}},
$$

where $W_{n}$ is the nonevaporable water content of specimen, (\%); $W_{1}$ is the mass of specimen at $105^{\circ} \mathrm{C}$ (i.e., dried mass of specimen), (g); $W_{2}$ is the mass of specimen at $1000^{\circ} \mathrm{C},(\mathrm{g}) ; L_{s s c}$ is a coefficient taking into account the loss on 
Table 1: Chemical compositions of steel slag and cement (\%).

\begin{tabular}{lccccccccc}
\hline Materials & $\mathrm{CaO}$ & $\mathrm{SiO}_{2}$ & $\mathrm{Al}_{2} \mathrm{O}_{3}$ & $\mathrm{Fe}_{2} \mathrm{O}_{3}$ & $\mathrm{MgO}$ & $\mathrm{K}_{2} \mathrm{O}$ & $\mathrm{SO}_{3}$ & $\mathrm{P}_{2} \mathrm{O}_{5}$ & $\mathrm{Others}$ \\
\hline Steel slag powder & 46.28 & 16.75 & 2.29 & 22.17 & 5.49 & 0.03 & 0.25 & 2.54 & 4.20 \\
Quartz powder & 1.93 & 95.30 & 0.70 & - & 0.65 & 0.21 & - & - & 1.21 \\
Cement & 62.13 & 20.76 & 4.58 & 3.27 & 3.13 & 0.75 & 2.80 & 0.12 & 2.46 \\
\hline
\end{tabular}

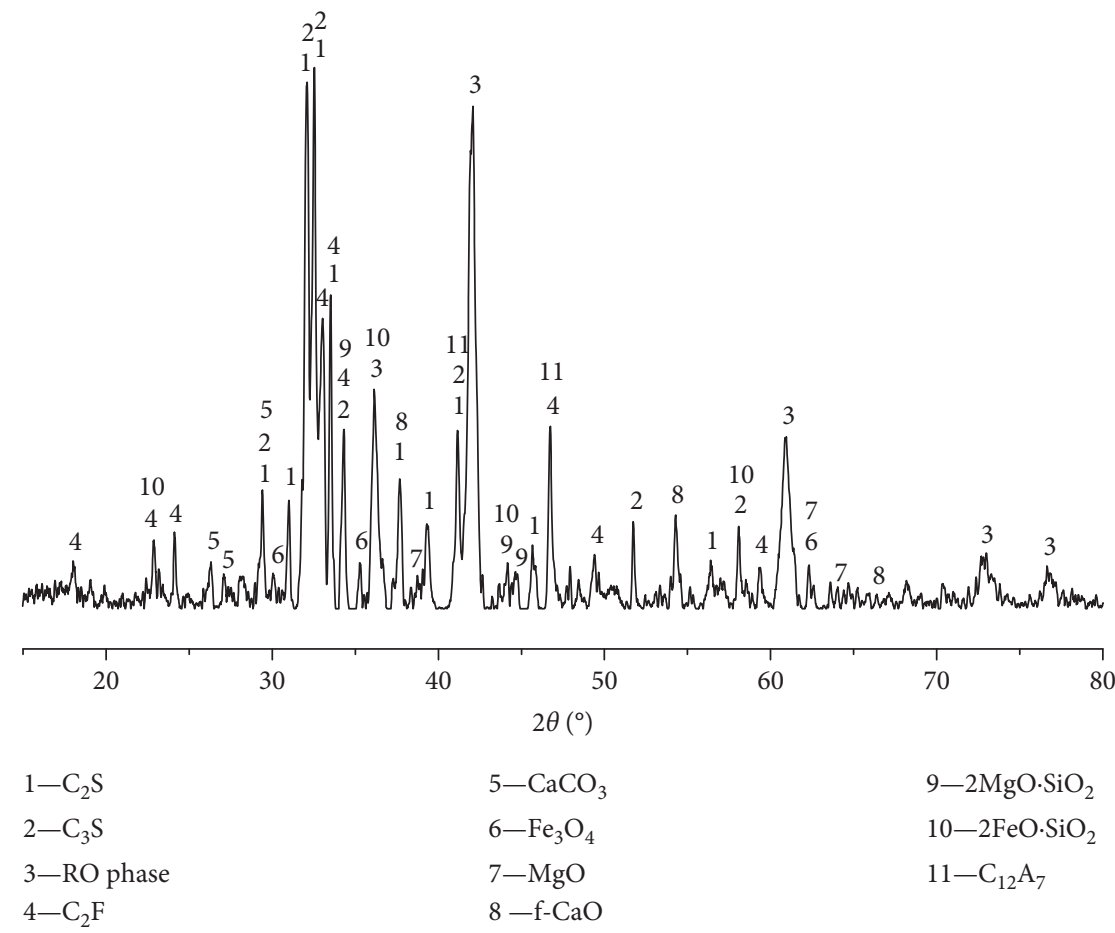

FIGURE 1: XRD pattern of steel slag used in this study.

TABle 2: Median diameters of steel slag and quartz powder $(\mu \mathrm{m})$.

\begin{tabular}{lcccc}
\hline Materials & $\begin{array}{c}10 \sim 15 \\
(R 1)\end{array}$ & $\begin{array}{c}15 \sim 20 \\
(R 2)\end{array}$ & $\begin{array}{c}20 \sim 30 \\
(R 3)\end{array}$ & $\begin{array}{c}60 \sim 70 \\
(R 4)\end{array}$ \\
\hline $\begin{array}{l}\text { Steel slag } \\
\text { powder }\end{array}$ & 14.52 & 18.16 & 29.63 & 65.36 \\
Quartz powder & 13.56 & 19.01 & 28.05 & 63.28 \\
\hline
\end{tabular}

ignition of cement and steel slag used in blend cement. The latter is calculated as follows:

$$
L_{s s c}=p_{s s} r_{s s}+p_{c} r_{c}
$$

where $p_{s s}$, and $p_{c}$ are the weight percentages of steel slag and cement in blended cement, respectively, and $r_{s s}$ and $r_{c}$ are the loss on ignition of steel slag and cement, respectively.

(b) The morphologies of hydration products of blended cement pastes containing steel slag powder were observed using a FEI Quanta 200F scanning electron microscope (SEM, 15 KV) under high vacuum condition.

(c) The porosities and pore size distribution of hardened cement pastes containing steel slag powder and quartz powder were determined using an Autopore 9500 Mercury intrusion porosimetry (MIP) from Micromeritics Instruments Corporation, whose pore analysis range was 3 to $4500000 \mathrm{~nm}$.

(d) Paste bars $(4 \times 4 \times 16 \mathrm{~cm})$ were prepared for the determination of the strength of blended cement pastes containing steel slag powder and quartz powders. The compressive strengths of paste specimens after curing for 3 days, 7 days, and 28 days at $20^{\circ} \mathrm{C}$ were measured according to the Chinese National Standard GB/T17671-1999.

\section{Influence of Steel Slag Powder Content on the Properties of Blended Cement}

3.1. Hydration Heat of Blended Cement Paste. The hydration heat curves of blended cements containing different amounts of steel slag powder are shown in Figure 3. As can be seen from Figure 3, the incorporation of steel slag powder prolongs the induction period of cement hydration, delays the second exothermic peak, and decreases the peak value. The second exothermic peak becomes broader. The higher the content of steel slag powder, the longer the induction period of blended cement, the later the appearance of the second exothermic peak, the lower the peak, and the broader the peak, showing that the addition of steel slag powder 


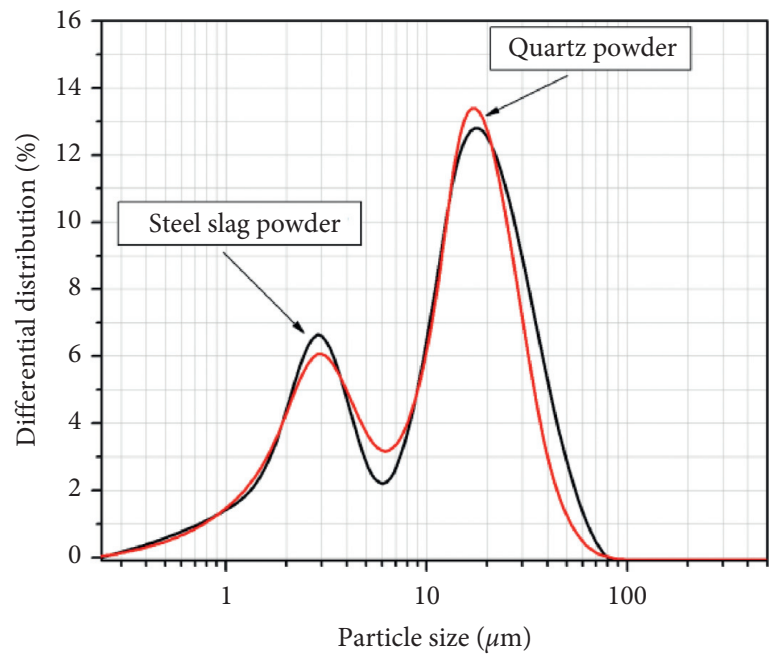

(a)

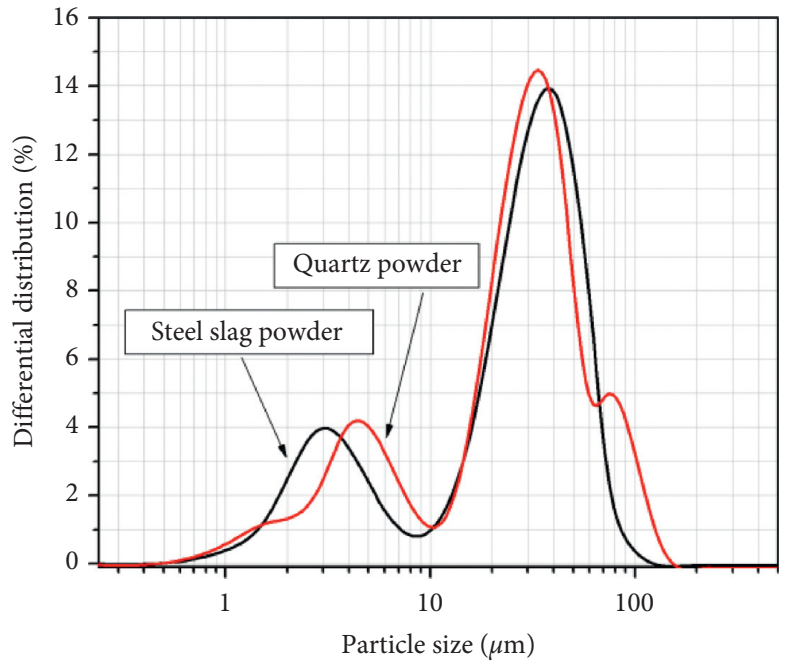

(c)

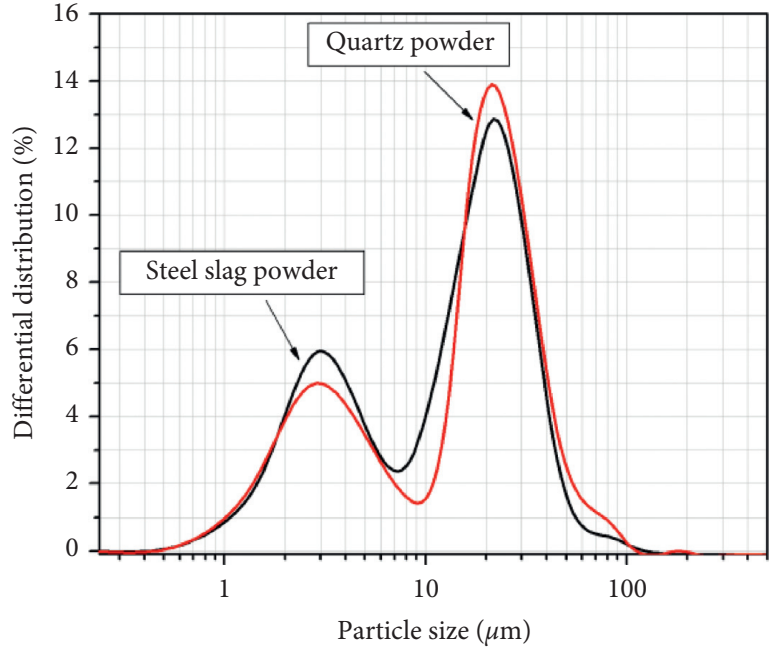

(b)

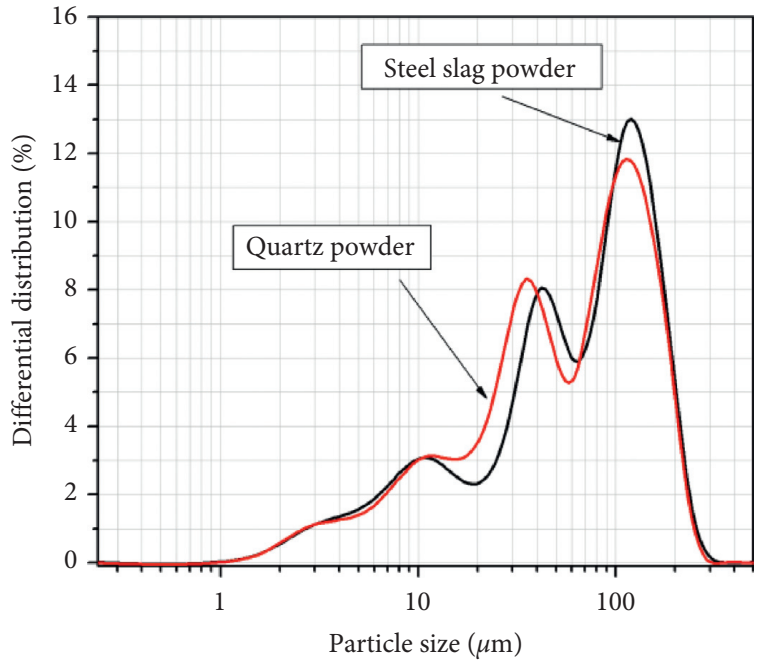

(d)

FIgure 2: Particle size distributions of steel slag and quartz powder. (a) R1. (b) R2. (c) R3. (d) R4.

TABLE 3: Mixing proportions of blended cements containing different amounts of steel slag powder.

\begin{tabular}{lcccc}
\hline Specimens & $\begin{array}{c}\text { Water-to-binder } \\
\text { ratio }\end{array}$ & Cement & $\begin{array}{c}\text { Mixture proportions (\%) } \\
\text { Steel slag powder }(R 2)\end{array}$ & Quartz powder $(R 2)$ \\
\hline Cement & & 100 & 0 & 0 \\
CSS20 & & 80 & 20 & 0 \\
CSS40 & & 60 & 40 & 0 \\
CSS60 & 0.35 & 40 & 60 & 0 \\
CS580 & & 20 & 80 & 0 \\
CQ20 & 80 & 0 & 20 \\
CQ40 & 60 & 0 & 60 \\
CQ60 & 40 & 0 & 80 \\
CQ80 & & 20 & 0 & 80 \\
\hline
\end{tabular}

slows down the hydration reaction rate of blended cement. This is mainly due to the low activity of steel slag powder, which slows down the overall hydration process of cement after replacing cement. In addition, the relatively high content of $\mathrm{P}_{2} \mathrm{O}_{5}$ or phosphate in the steel slag powder used will also delay the hydration process of cement. The heat release of the reference cement and the cement mixed with $20 \%$ steel slag powder is mainly concentrated before $30 \mathrm{~h}$, while the heat release of the high content (40\% and 50\%) of steel slag cement is mainly after $20 \mathrm{~h}$. The second exothermic peaks of steel slag cement mixed with $20 \% \sim 50 \%$ are about $2 /$ $3,2 / 5$, and $1 / 4$ of the reference cement, respectively. For the 
TABLE 4: Mixing proportions of blended cements containing steel slag powder with different particle sizes.

\begin{tabular}{|c|c|c|c|c|c|c|c|c|c|c|}
\hline \multirow{3}{*}{ Specimens } & \multirow{3}{*}{ Water-to-binder ratio } & \multicolumn{9}{|c|}{ Mixture proportions (\%) } \\
\hline & & \multirow[b]{2}{*}{ Cement } & \multicolumn{4}{|c|}{ Steel slag powder (SS) } & \multicolumn{4}{|c|}{ Quartz powder $(\mathrm{Q})$} \\
\hline & & & $R 1$ & $R 2$ & R3 & $R 4$ & $R 1$ & $R 2$ & $R 3$ & $R 4$ \\
\hline Cement & & 100 & & & & & & & & \\
\hline SSR1 & & 70 & 30 & & & & & & & \\
\hline SSR2 & & 70 & & & & & & & & \\
\hline SSR3 & & 70 & & & & & & & & \\
\hline SSR4 & 0.35 & 70 & & & & & & & & \\
\hline QR1 & & 70 & & 30 & & & & & & \\
\hline QR2 & & 70 & & & 30 & 30 & 30 & & & \\
\hline QR3 & & 70 & & & & & 30 & 30 & & \\
\hline QR4 & & 70 & & & & & & & 30 & 30 \\
\hline
\end{tabular}

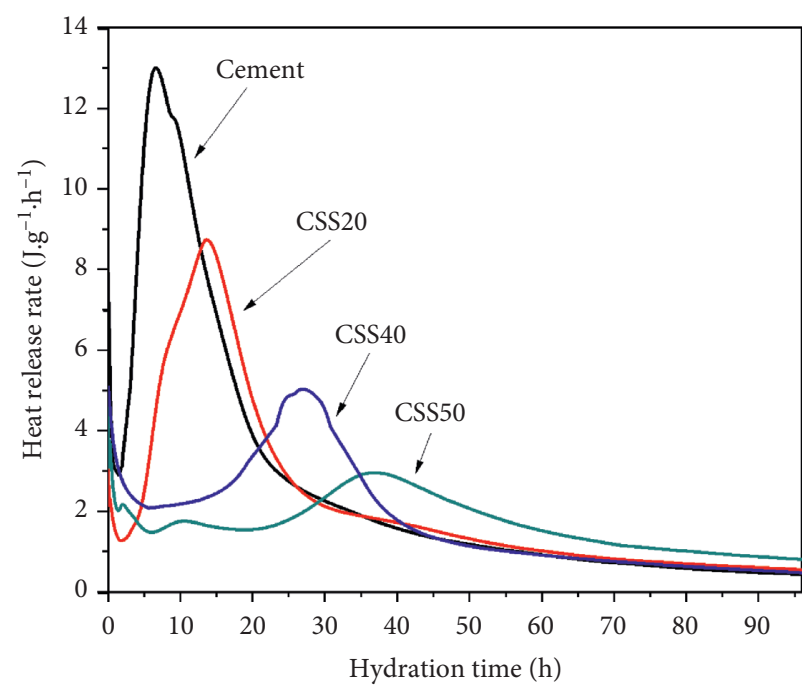

(a)

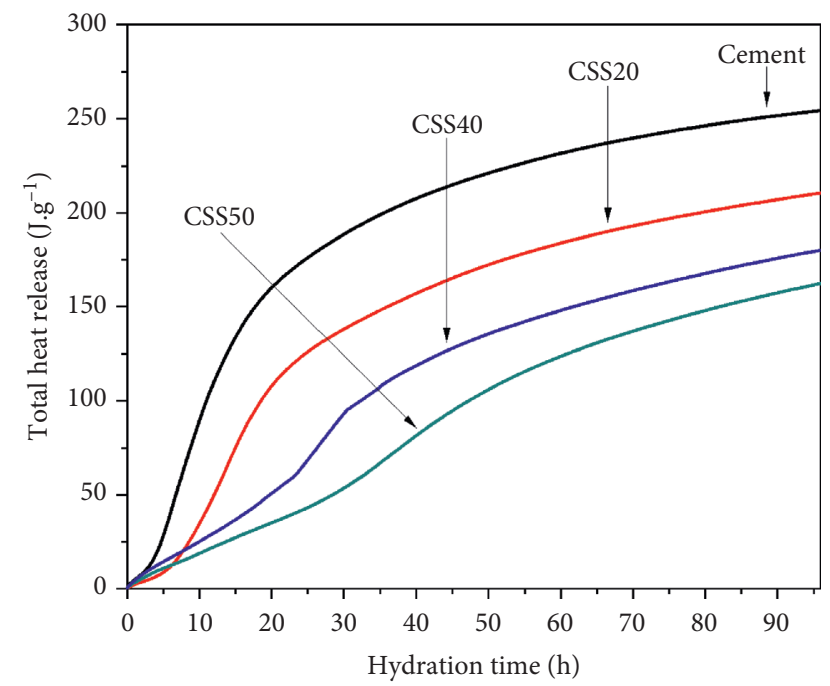

(b)

Figure 3: Hydration heat curves of blended cement containing different amounts of steel slag powder. (a) Exothermic rate. (b) Total heat release.

total heat release, as the amount of steel slag powder increases, the blended cement's complete heat release decreases gradually. The blended cement's cumulative heat release mixed with $20 \%$ to $50 \%$ steel slag powder was 0.83 , 0.71 , and 0.64 of the reference cement samples, respectively, after $96 \mathrm{~h}$ hydration time.

\subsection{Nonevaporable Water Content of Blended Cement Paste.} The nonevaporable water content of blended cements containing different amounts of steel slag powder at 28 days is shown in Figure 4 . It can be seen from Figure 4 that the nonevaporable water content of the blended cement gradually decreases with the increase of steel slag powder content. The addition of a small amount of steel slag powder (such as $20 \%$ content) has little effect on the nonevaporable water content of the blended cement. When the steel slag powder content is greater than $40 \%$, the nonevaporable water content of the blended cement is significantly reduced. Moreover, there is a binomial relationship between the nonevaporable water content of blended cement and the amount of steel slag powder.
In order to further reflect the contribution of steel slag powder to the nonevaporable water content of blended cement, the quartz powder (inert material) with similar particle size distribution was selected as a reference. Moreover, it is assumed that the nonevaporable water content of blended cement is generated by the hydration superposition of clinker and steel slag. Furthermore, the influence coefficient of nonevaporable water content, $\phi_{W n}$, is used to represent the contribution of steel slag powder to the nonevaporable water content of the blended cement. The calculation formula is as follows:

$$
\Phi_{W n}=\frac{W n_{(C S S)}-W n_{(C Q)}}{W n_{(C S S)}} \times 100 \%,
$$

where $W n_{(C S S)}$ is the nonevaporable water content of the blended cement paste containing steel slag powder; and $W n_{(C Q)}$ is the nonevaporable water content of the blended cement paste containing quartz powder.

As shown in Figure 5, the influence coefficient of nonevaporable water content $\left(\phi_{W n}\right)$ gradually increases with the increase of the amount of steel slag powder, and the two 


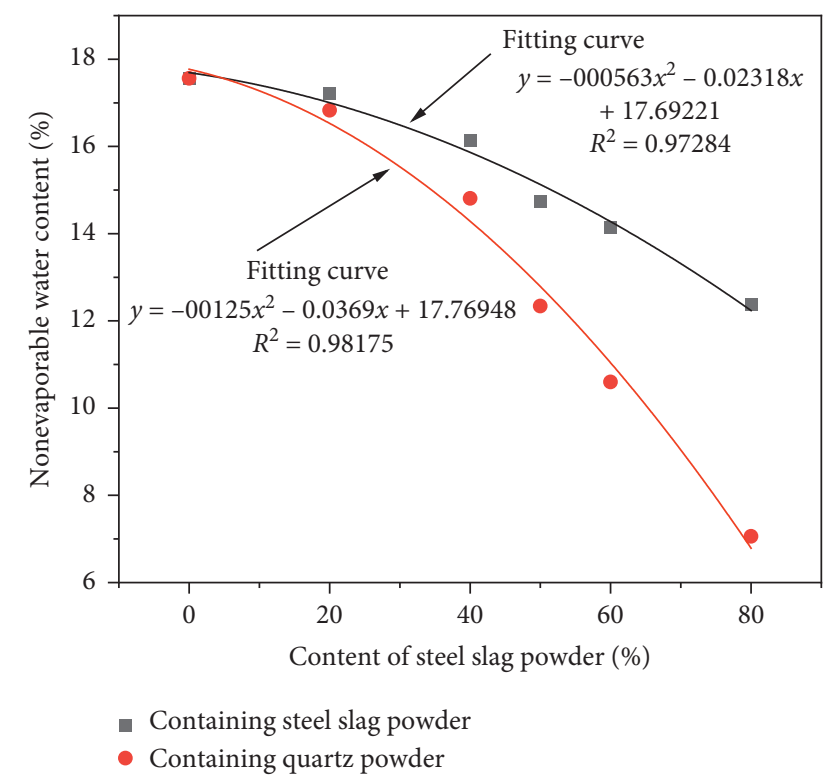

Figure 4: Nonevaporable water content of blended cement containing different amounts of steel slag powder.

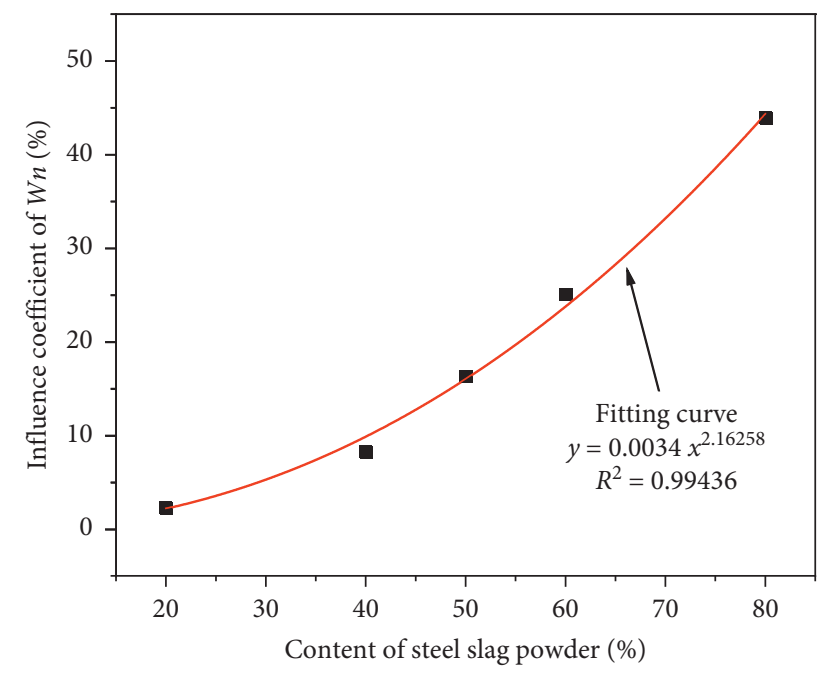

Figure 5: Influence coefficient of steel slag powder content on nonevaporable water content of blended cement.

meet an exponential relationship. When the amount of steel slag powder is less than $40 \%, \phi_{W n}$ of blended cement is less than $10 \%$, which also indicates that the contribution of steel slag powder to the nonevaporable water content of blended cement is much less than that of cement clinker.

3.3. Strength of Blended Cement Paste. The compressive strengths of blended cement paste containing different amounts of steel slag powder are shown in Figure 6. It can be seen from the figure that the amount of steel slag powder has a significant effect on the strength of cement paste. The compressive strengths of blended cement paste at various ages decrease with the increase of steel slag powder content. Steel slag powder has the most obvious effect on the $3 \mathrm{~d}$

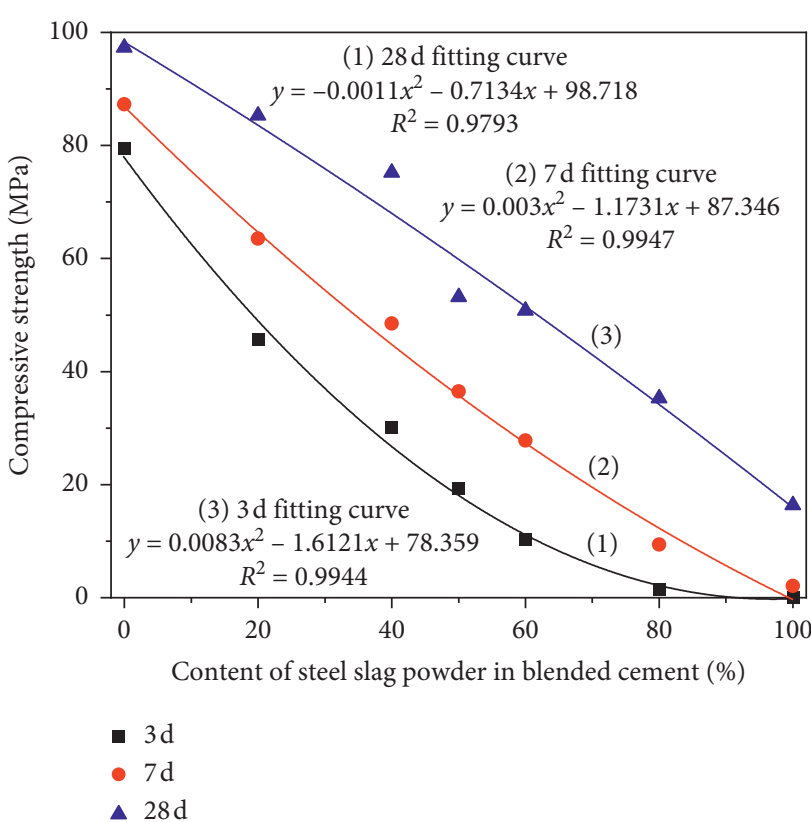

FIgURE 6: Strength and fitting result of blended cement containing steel slag powder.

strength of blended cement. For example, when $20 \%$ steel slag powder is added, the $3 \mathrm{~d}$ strength of blended cement decreases by $42.6 \%$, while the $28 \mathrm{~d}$ strength decreases by only $12.3 \%$. From the fitting results of the strength of blended cement and the amount of steel slag powder, it can be seen that the influence of the amount of steel slag powder on the strength of the blended cement at various ages conforms to the binomial function relationship.

Similarly, the quartz powder, an inert material with a similar particle size distribution, is selected as a reference, and it is assumed that the strength of the blended cement is only produced by the hydration of the clinker and steel slag. Therefore, the strength influence coefficient, $\phi_{S}$, is used to represent the contribution of steel slag powder to the strength of blended cement. The calculation formula is as follows (4), and the result is shown in Figure 7:

$$
\Phi_{S}=\frac{S_{C S S}-S_{C Q}}{S_{C S S}} \times 100 \%,
$$

where $S_{C S S}$ is the compressive strength of the blended cement paste containing steel slag powder and $W n_{(C Q)}$ is the compressive strength of the blended cement paste containing quartz powder.

The results in Figures $7(a)$ and $7(b)$ show that the compressive strength of the blended cement paste containing steel slag powder at the age of 3 days is lower than that of the blended cement containing quartz powder, but the result is the opposite at the age of 28 days. The reason is that the quartz powder is an inert material and does not participate in the hydration reaction. It plays a "dilution" effect on the blended cement system in the early stage, thereby increasing the actual water-to-cement ratio of the clinker minerals involved in hydration reaction and promoting its early hydration reaction degree. By contrast, the 


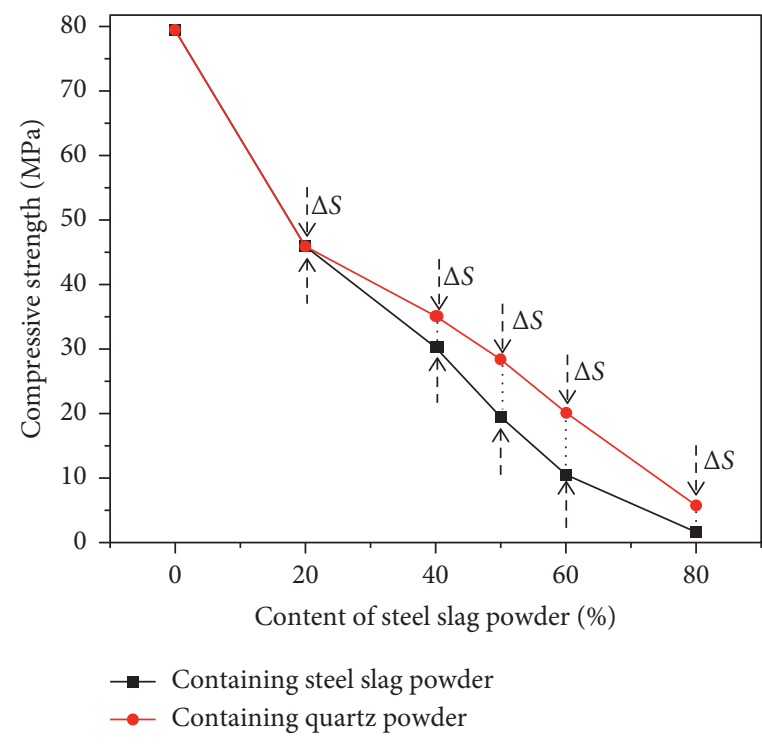

(a)

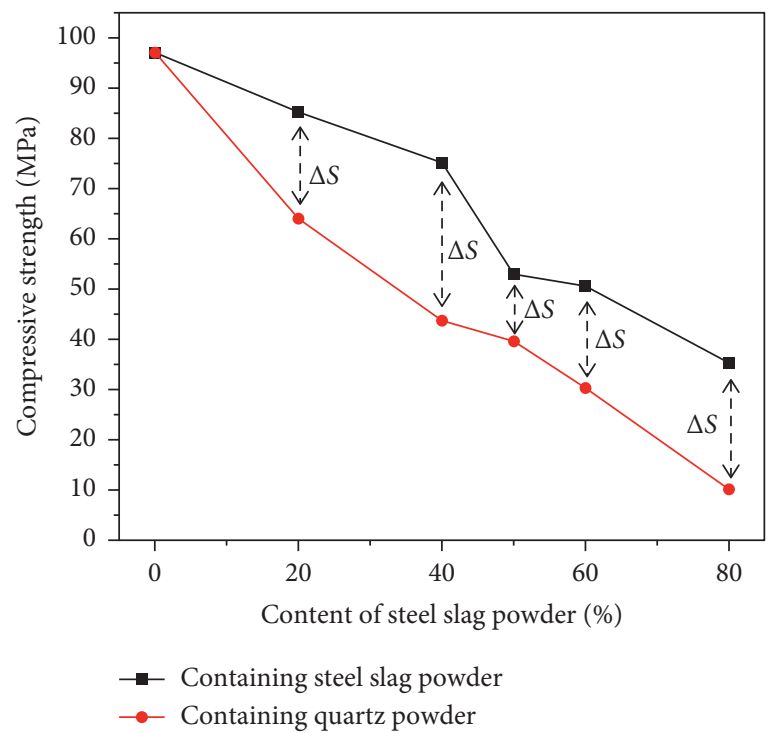

(b)

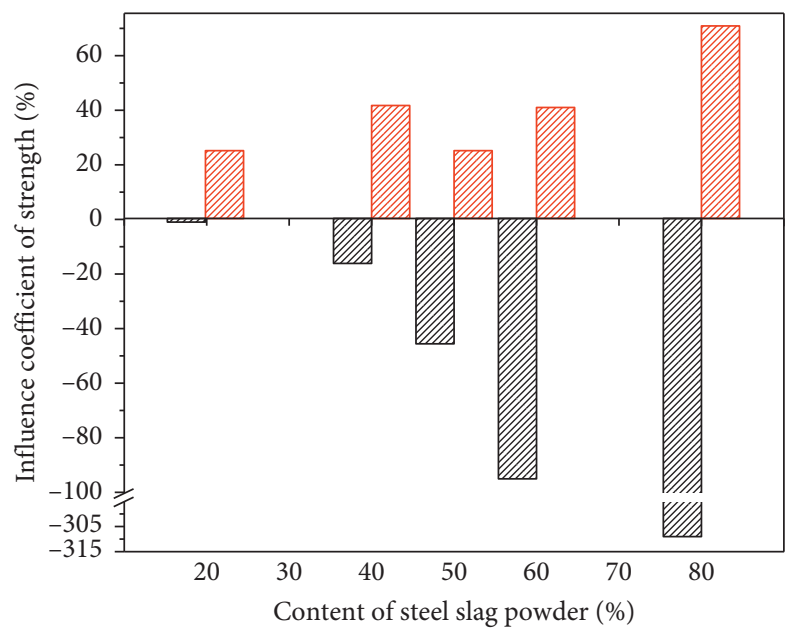

$3 \mathrm{~d}$

$28 \mathrm{~d}$

(c)

FiguRE 7: Influence coefficient of steel slag powder on compressive strength of blended cement. (a) $3 \mathrm{~d}$. (b) $28 \mathrm{~d}$. (c) Influence coefficient of strength.

steel slag powder has a low hydration degree at the age of 3 days due to the low early activity, so its contribution to the early strength of blended cement is very small. However, at the same time, it needs to occupy the water in the system to dissolve the mineral ions so that the water involved in the hydration reaction of clinker mineral is relatively reduced, delaying its hydration process, resulting in its strength contribution is also reduced.

However, with the prolongation of the age, the hydration degree of steel slag powder in blended cement gradually increases. By the age of $28 \mathrm{~d}$, the strength of blended cement produced by hydration of clinker and steel slag will exceed that of blended cement containing quartz powder. It can be seen intuitively from Figure 7(c) that the strength influence coefficient of the blended cement paste,
$\phi_{S}$, is negative at the age of $3 \mathrm{~d}$. The greater the amount of steel slag powder, the greater the negative influence on the compressive strength. However, $\Phi_{S}$ is positive at the age of 28 days and exceeds $25 \%$.

3.4. Morphology of Blended Cement Paste. The morphologies of blended cement containing different amounts of steel slag powder $(R 2)$ at 3 days and 28 days are shown in Figure 8.

It can be seen from Figure 8(a) that the morphologies of blended cement have changed obviously with the increase of the amount of steel slag powder. Blended cement with a small additional amount (such as $20 \%$ ) of steel slag powder has more hydration products, such as amorphous C-S-H gels and $\mathrm{Ca}(\mathrm{OH})_{2}$, and compact structure with fewer pores. 

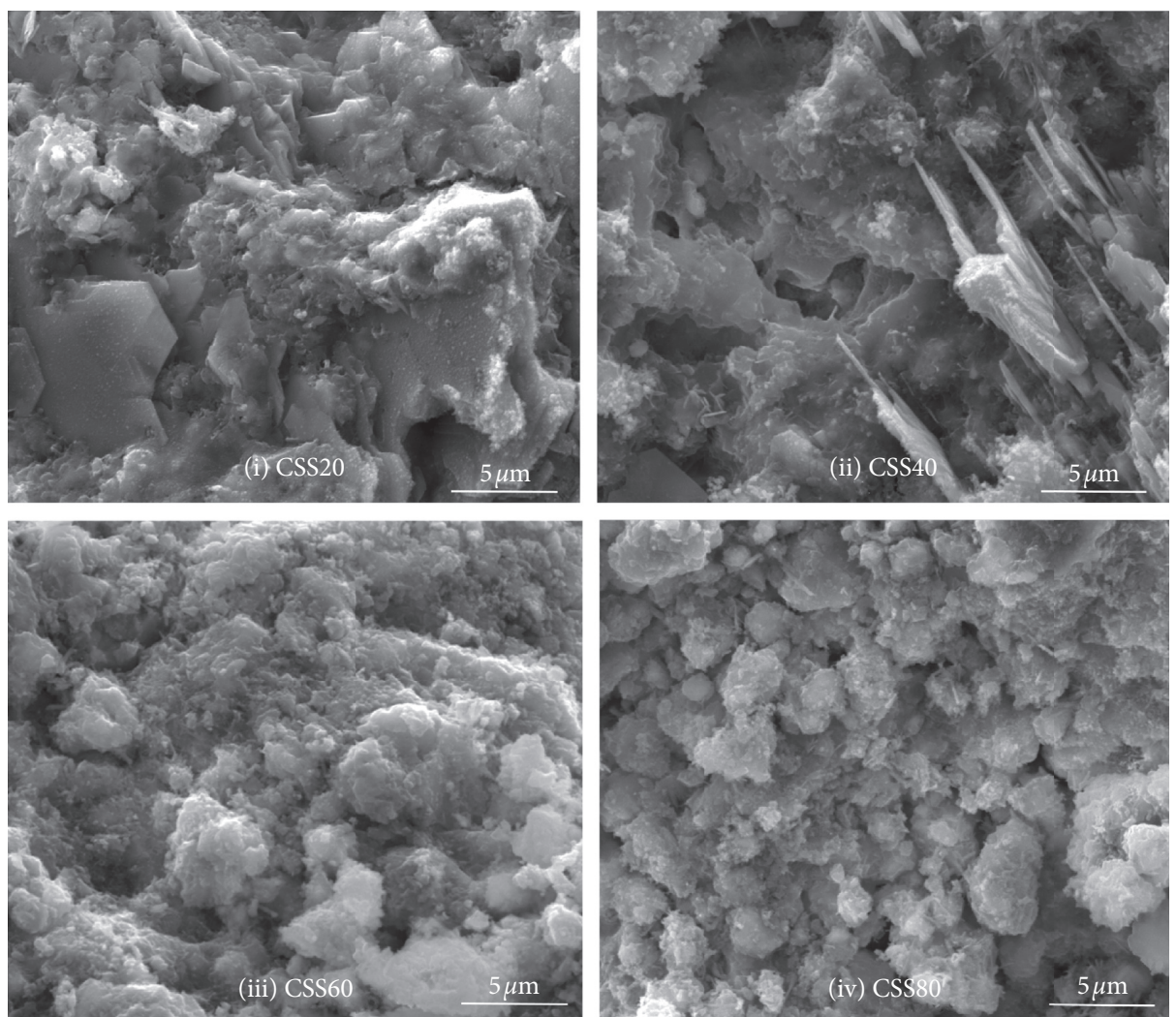

(a)
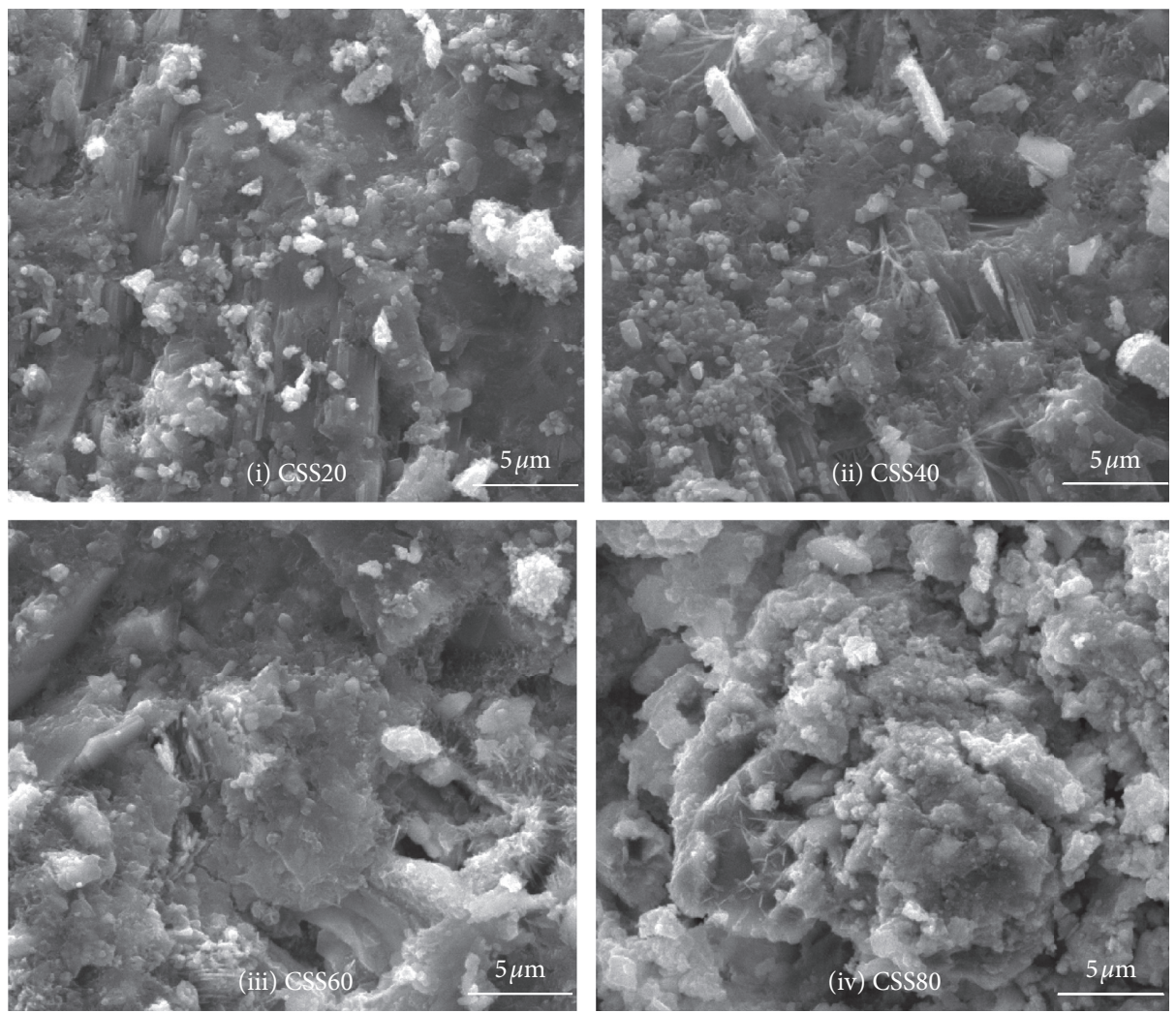

(b)

Figure 8: Morphology of blended cement containing different amounts of steel slag powder. (a) $3 \mathrm{~d}$. (b) $28 \mathrm{~d}$. 
Moreover, the product system mainly consists of cement hydration products, in which a very small number of hydration products of steel slag are wrapped. On the contrary, when the addition amount of steel slag powder is high (such as $80 \%$ ), the hydration products of steel slag are the main components in the blended cement, but the hydration products in the system are initially formed with scattered distribution and loose structure with more pores and poor compactness.

Figure 8(b) shows that the hydration products of blended cement increased significantly at 28 days, and the amorphous C-S-H gels accumulated on one another and were basically connected as a whole. Moreover, with the increase of the addition amount of steel slag powder, the change of the morphology and microstructure of blended cement at 28 days is relatively smaller than that at 3 days. This is due to the fact that the hydration of steel slag at 28 days is obviously sufficient compared with that at 3 days, and the hydration products generated continuously fill the pore structure and improve the compactness in the system during 28 days. Thereout, the effect of steel slag powder content on the morphology and microstructure of the hydration products of blended cement is relatively weakened at 28 days, which is consistent with the above-mentioned influence of steel slag powder content on the strength of blended cement.

3.5. Pore Structure of Blended Cement Paste. The pore volume distribution and aperture parameter value of blended cement paste containing steel slag powder at 28 days are shown in Figures 9 and 10, respectively. It can be seen from Figure 9 that the pore size of blended cement paste is mainly distributed in the range of $3-10 \mathrm{~nm}$ and $30-100 \mathrm{~nm}$. The higher the content of steel slag powder in blended cement, the higher the cumulative pore volume of the paste. As shown in Table 5, the total pore volume, median pore size, and porosity of the blended cement paste gradually increase with the increase of steel slag powder content. The total pore volume increased from $0.1178 \mathrm{~mL} / \mathrm{g}$ to $0.1995 \mathrm{~mL} / \mathrm{g}$, the median pore size increased from $21.1 \mathrm{~nm}$ to $34.4 \mathrm{~nm}$, and the porosity increased from $21.62 \%$ to $34.80 \%$. In particular, the pores of blended cement paste with a large amount of steel slag increased significantly.

\section{Effect of Particle Size of Steel Slag Powder on the Properties of Blended Cement}

4.1. Nonevaporable Water Content of Blended Cement Paste. The nonevaporable water contents of blended cement pastes containing $30 \%$ steel slag powder or quartz powder with different particle sizes at 28 days are shown in Figure 10. The results show that the nonevaporable water contents of blended cement paste are gradually decreased with the increase of particles' size of steel slag powder. However, the nonevaporable water contents of blended cement paste containing quartz powder show an opposite law. The reason is that the quartz powder does not participate in the hydration reaction and plays a "dilution" effect on the blended cement system. The larger the particle size of quartz powder, the stronger the "dilution" effect in a blended cement system. Thus, the hydration reaction of the clinker minerals will be promoted, resulting in a relatively high nonevaporable water content.

As shown in Figure 11, $\Phi_{W n}$ gradually decreases with the increase of particles' size of steel slag powder. When the particle size of steel slag powder is $R 1, \Phi_{W n}$ of blended cement is $18.32 \%$, and when the particle size of steel slag powder increases to $R 2$, the influence coefficient decreases to $9.5 \%$. It indicates that $30 \%$ steel slag powder has little contribution to the nonevaporable water content of blended cement, and its contribution is also greatly affected by particle size.

4.2. Porosity of Blended Cement Paste. The porosities of blended cement pastes containing 30\% steel slag powder or quartz powder with different particle sizes at 28 days are shown in Figure 12. The results show that the porosities of blended cement paste gradually increase with the increase of particle size of steel slag powder or quartz powder. The reason is that the quartz powder is an inert material and only plays a filling role in blended cement. Therefore, quartz powder with a particle size distribution similar to steel slag powder can be used to approximate the physical filling effect of steel slag powder on blended cement.

It can be seen from Figure 12 that the porosity of blended cement paste decreases with the decrease of quartz particle size; that is, the physical filling effect of steel slag powder on blended cement is enhanced with the decrease of particle size. Comparing the porosities of the blended cement paste with steel slag powder and the quartz powder, it can be seen that the smaller the particle size, the greater the gap between the two. This is because the steel slag powder with a small particle size has relatively high hydration activity, which promotes the production of more hydration products and further fills the pores of the paste, thereby reducing the porosity of paste. The filling effect caused by the hydration reaction of steel slag powder can be regarded as the chemical filling role $\left(\Phi_{F}\right)$ of steel slag powder on blended cement. The calculation formula is as follows (5), and the result is shown in Figure 13.

$$
\Phi_{F}=\frac{P_{C Q}-P_{C S S}}{100-P_{C S S}} \times 100 \%,
$$

where $P_{C S S}$ is the porosity of the blended cement paste containing steel slag powder; $S_{C Q}$ is the porosity of the blended cement paste containing quartz powder.

As shown in Figure 13, the chemical filling role gradually weakens with the increase of the particle size of steel slag powder. Generally, the chemical filling role of steel slag powder on the blended cement is relatively small. The chemical filling role of $30 \%$ steel slag powder with different particle sizes in blended cement paste is only in the range of $1.13 \%-5.06 \%$.

4.3. Strength of Blended Cement Paste. The strengths of blended cement pastes containing $30 \%$ steel slag powder or 


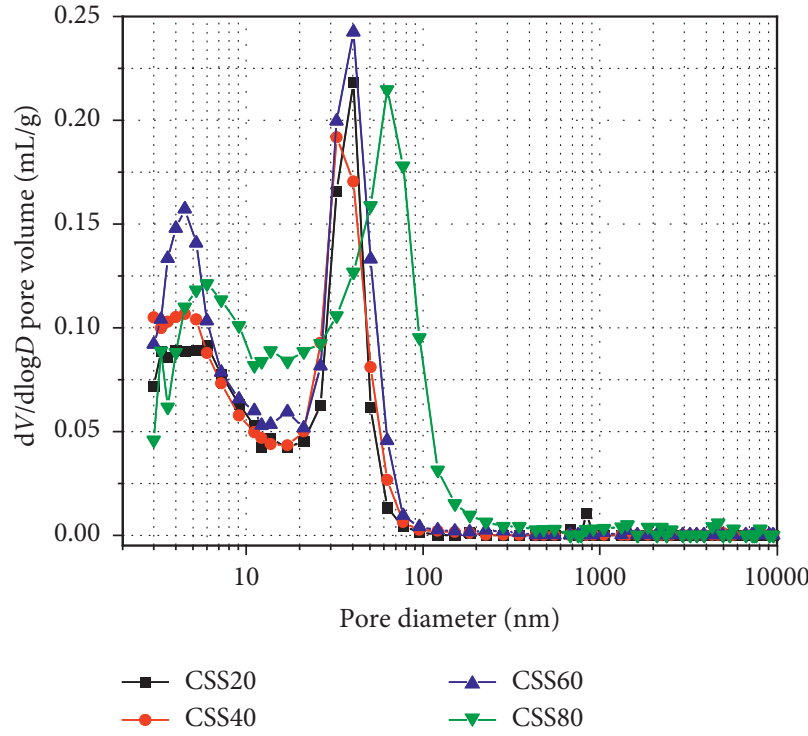

(a)

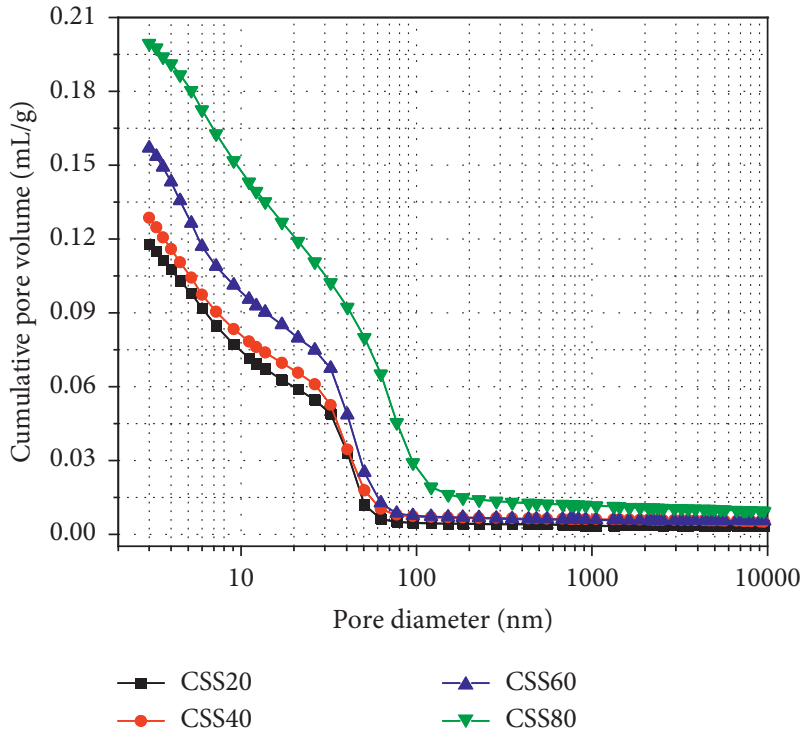

(b)

Figure 9: Pore volume distribution of blended cement paste containing steel slag powder. (a) Differential distribution. (b) Cumulative distribution.

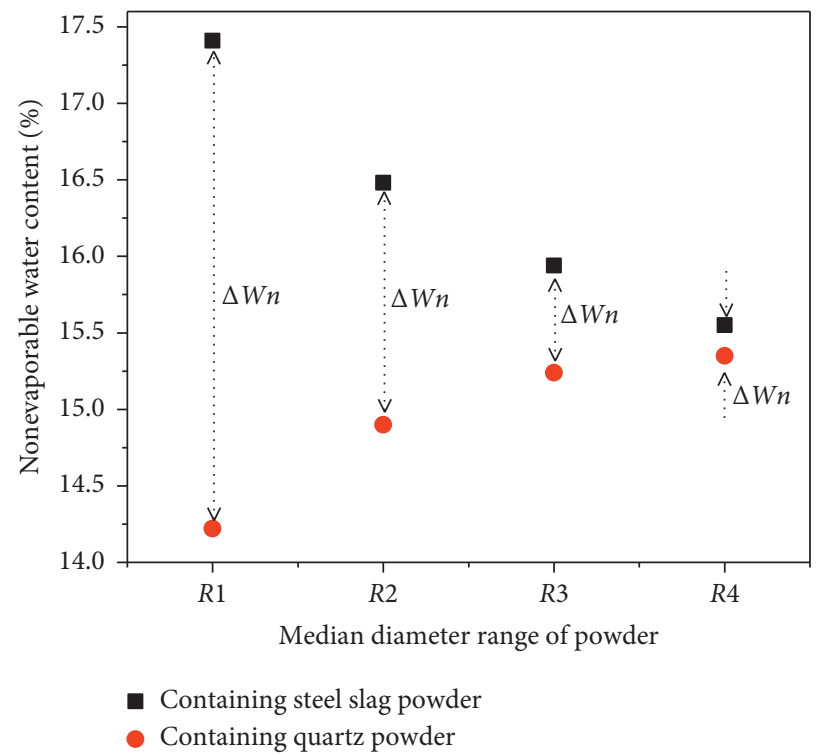

FIGURE 10: Nonevaporable water content of blended cement containing steel slag powder with different particle sizes.

TABLE 5: Aperture parameters of blended cement paste containing steel slag powder.

\begin{tabular}{lccc}
\hline Specimens & Total pore volume $(\mathrm{mL} / \mathrm{g})$ & Median pore size $(\mathrm{nm})$ & Porosity $(\%)$ \\
\hline CSS20 & 0.1178 & 21.1 & 21.62 \\
CSS40 & 0.1286 & 22.5 & 23.61 \\
CSS60 & 0.1569 & 23.2 & 28.85 \\
CSS80 & 0.1995 & 34.4 & 34.80 \\
\hline
\end{tabular}




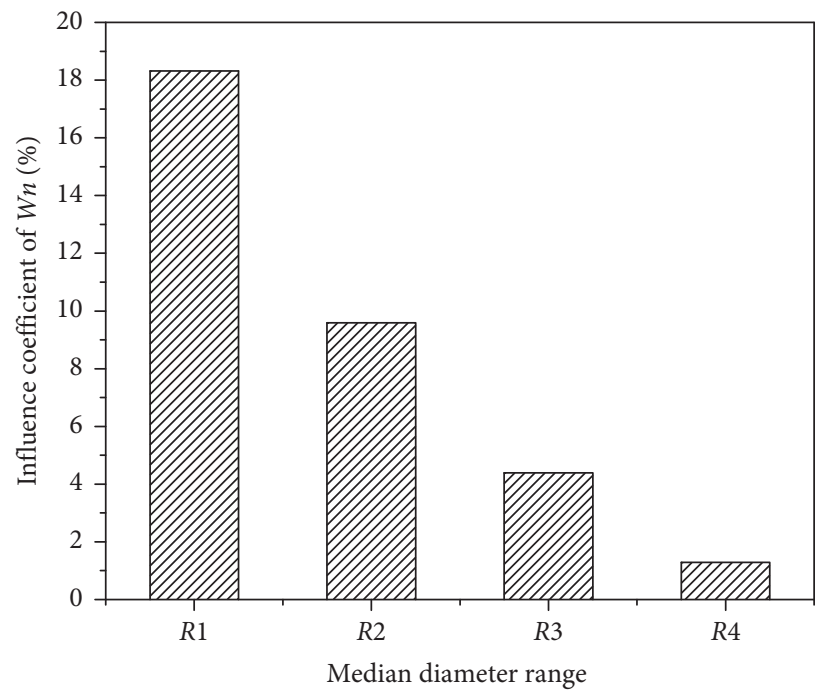

Figure 11: Influence coefficient of steel slag powder with different particle sizes on nonevaporable water content of blended cement.

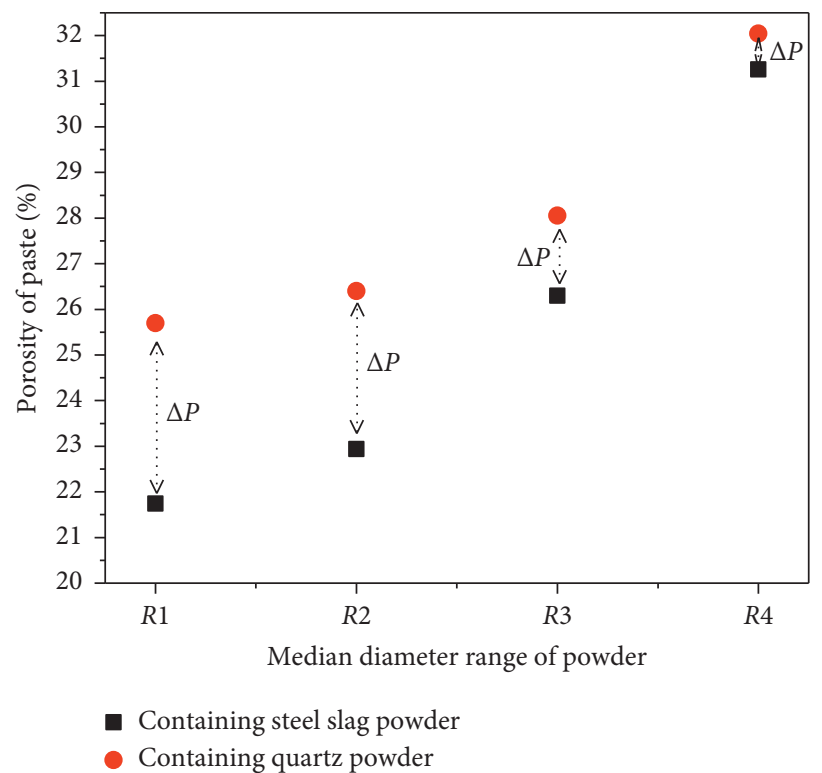

Figure 12: Effects of steel slag and quartz powder on the porosity of blended cement.

quartz powder with different particle sizes at 28 days are shown in Figure 14. The results show that the particle size of steel slag powder has different effects on the $3 \mathrm{~d}$ and $28 \mathrm{~d}$ strength of the blended cement paste. With the increase of particle size of the steel slag powder, the $3 \mathrm{~d}$ strength of the blended cement paste first increases and then decreases, while the $28 \mathrm{~d}$ strength gradually decreases. The reason is similar to the explanation in Section 3.3.

As shown in Figure 15, the results show that the influence coefficient of steel slag powder on the compressive strength of the blended cement paste is negative at 3 days, and the smaller the particle size of steel slag powder, the greater the negative impact on compressive strength. At the age of 28 days, the influence coefficient of strength is positive and in the range of $25 \%-30 \%$. This is also just close to the amount of steel slag powder in the blended cement in this study.
4.4. Morphology of Blended Cement Paste. The morphologies of blended cement containing steel slag powder with different particle size at 3 days and 28 days are shown in Figure 16.

It can be seen from Figure 16(a) that the type and morphology of the hydration products of the four kinds of blended cement basically did not change much, but the compactness of the paste structure gradually increased slightly with the increase of the particle size of steel slag. Figure 16(b) shows an opposite rule; that is, with the increase of the particle size of steel slag, the hydration products of blended cement gradually decrease at 28 days, the structure of paste becomes loose, and the compactness also gradually decreases. This is consistent with the abovementioned influence of particle size of steel slag powder on the strength of blended cement. The reason is that the early 


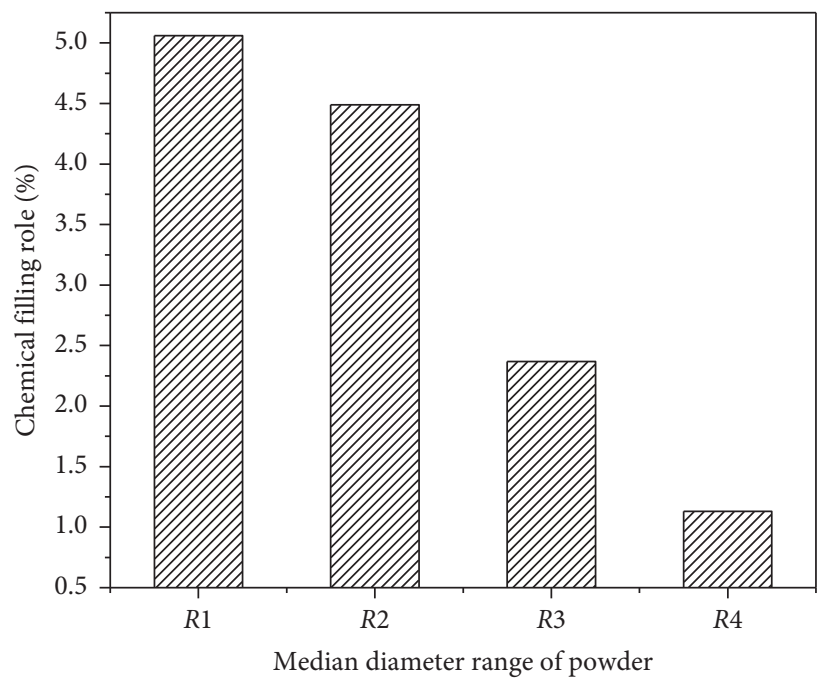

FIGURE 13: Chemical filling role of steel slag powder with different particle sizes in blended cement paste.

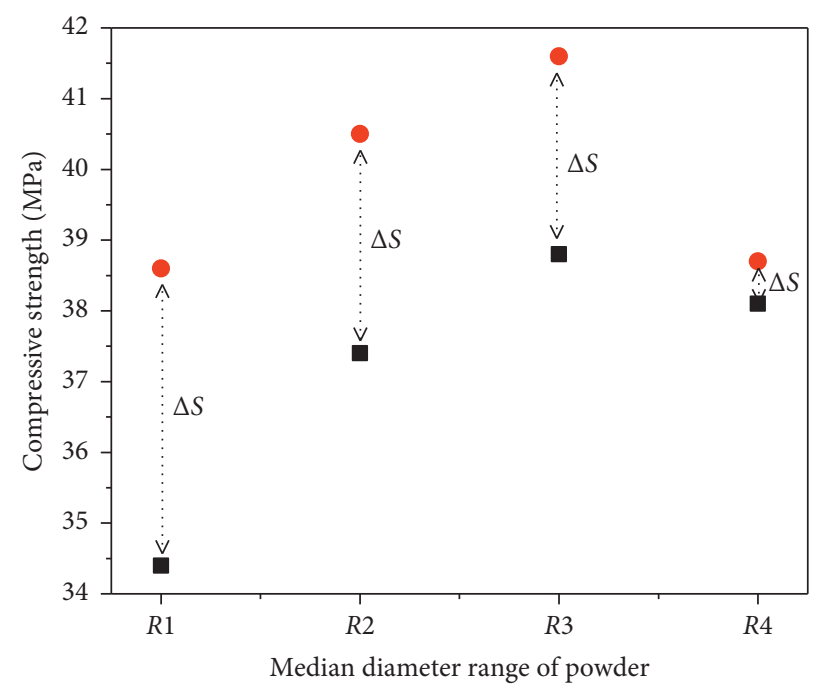

Containing steel slag powder

- Containing quartz powder

(a)

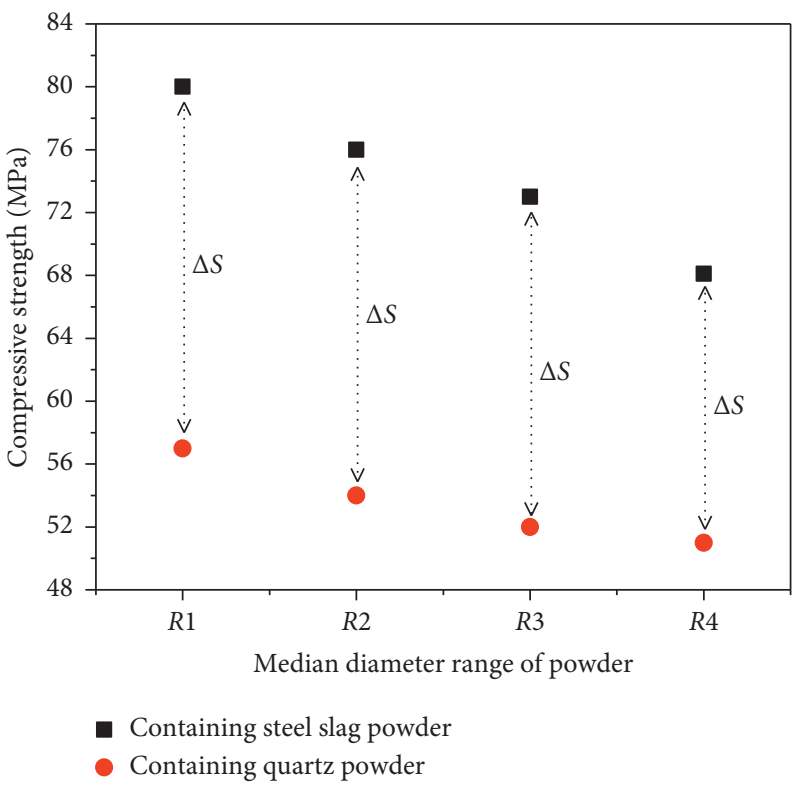

(b)

Figure 14: Compressive strength blended cement paste containing different particle size steel slag and quartz powder. (a) $3 \mathrm{~d}$. (b) $28 \mathrm{~d}$.

activity of steel slag is very low, and the steel slag with a large particle size basically would not participate in the hydration reaction at 3 days, which actually generates "dilution effect" to the water-cement ratio of the cement component in blended cement system. The "dilution effect," in other words, is to increase the water-cement ratio of the cement component in the blended cement system, so the hydration of the cement component in blended cement is accelerated. The smaller the steel slag particle size, the weaker the dilution effect, so the microstructure of blended cement containing steel slag powder with large particle size is relatively good at 3 days. However, with the extension of age, the hydration reaction of steel slag with a small particle size would gradually improve, and its hydration products can further fill the structure of blended cement to make it more compact in later ages. While the hydration effect of steel slag with a large particle size is lower than that of steel slag with small particle size, the blended cement containing steel slag with smaller particle size has more hydration products and a relatively compact microstructure. It also explains the effect rule of particle size of steel slag on the macroscopic properties of blended cement from the view of morphology and microstructure of hydration products. 


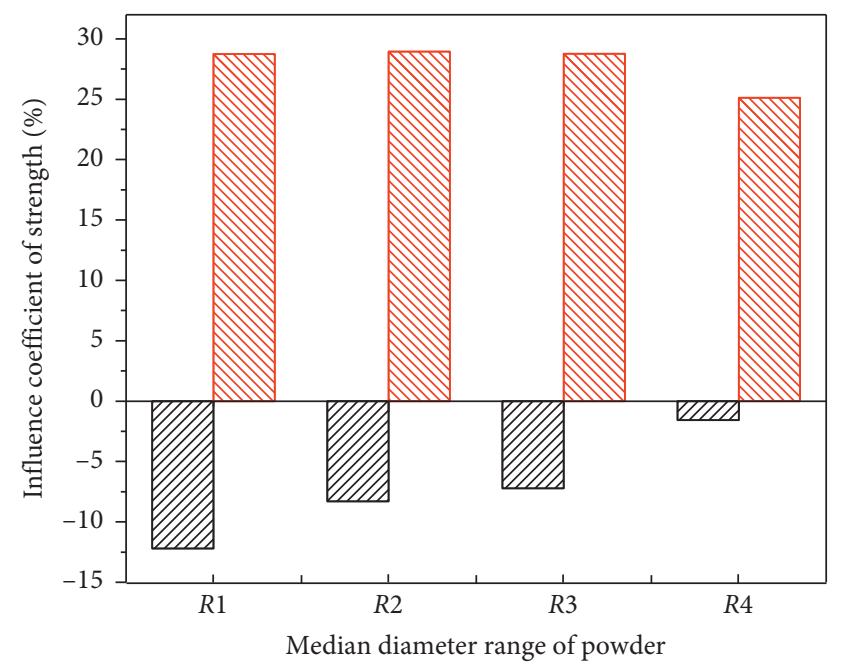

VIII 3d

MUV $28 \mathrm{~d}$

FiguRE 15: Strength contribution ratio of different particle size steel slag powder in blended cement.
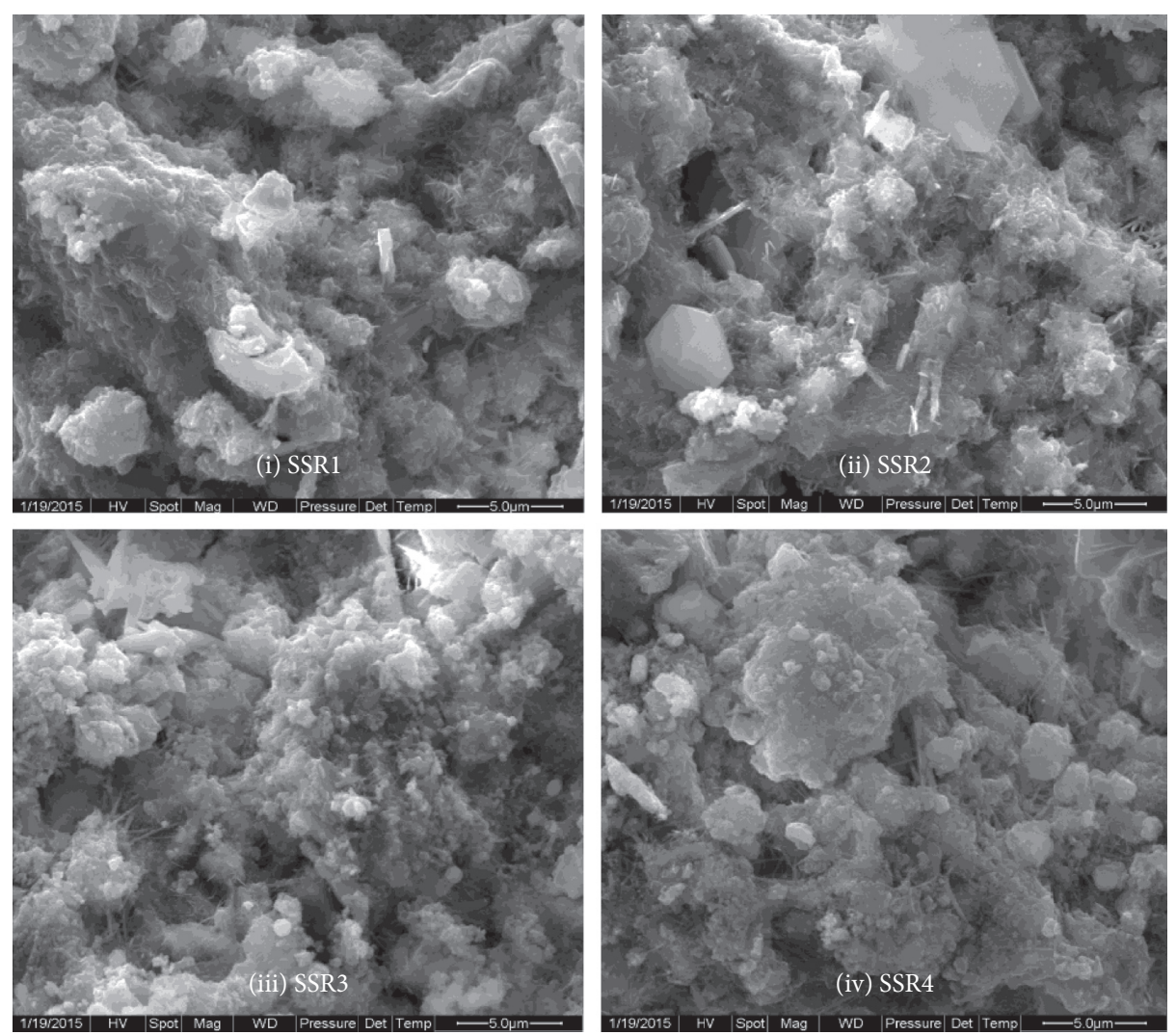

(a)

FIgURE 16: Continued. 

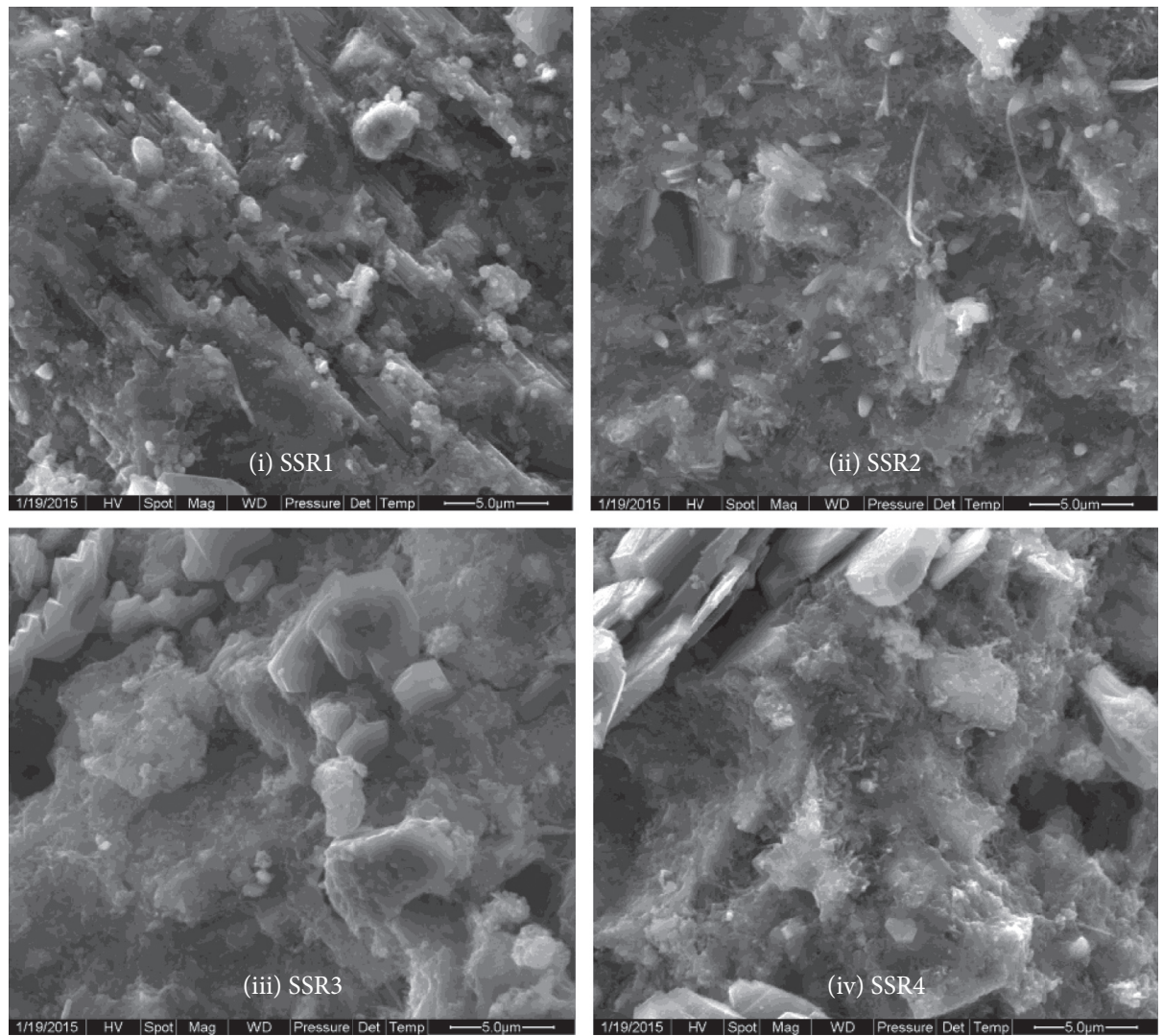

(b)

FIgURE 16: Morphology of blended cement containing steel slag powder with different sizes. (a) $3 \mathrm{~d}$. (b) $28 \mathrm{~d}$.

\section{Conclusions}

(1) The influence coefficient of nonevaporable water content $\left(\Phi_{W n}\right)$ of blended cement paste is in an exponential relationship with the amount of steel slag powder. Moreover, at a dosage of $30 \%, \Phi_{W n}$ gradually decreases with the increase of the steel slag powder particle size.

(2) Both the early and late compressive strengths of blended cement paste are in a binomial relationship with the amount of steel slag powder. With the increase of particle size of the steel slag powder, the $3 \mathrm{~d}$ strength of the blended cement paste first increases and then decreases, while the $28 \mathrm{~d}$ strength gradually decreases. The influence coefficient of steel slag powder on the compressive strength of blended cement paste is negative at the age of 3 days. The greater the amount of steel slag powder or the smaller the particle size, the greater the negative influence on the compressive strength; and at the age of 28 days, the strength influence coefficient is positive.

(3) The pore size of the blended cement paste containing steel slag powder is mainly distributed in the range of $3-10 \mathrm{~nm}$ and $30-100 \mathrm{~nm}$, and both the median pore size and porosity increase gradually with the increase of steel slag powder content. The chemical filling role of steel slag powder on the blended cement paste gradually weakens with the increase of its particle size. The chemical filling role of $30 \%$ steel slag powder with different particle sizes in the blended cement paste is only in the range of $1.13 \%-5.06 \%$. The hydration products of blended cement containing steel slag powder are mainly amorphous C-S$\mathrm{H}$ gel and platy $\mathrm{Ca}(\mathrm{OH})_{2}$, and its density is consistent with the law of its porosity.

\section{Data Availability}

The data used to support the findings of this study are included within the article.

\section{Conflicts of Interest}

The authors declare that they have no conflicts of interest.

\section{Acknowledgments}

This work was financially supported by the National Natural Science Foundation of China (No. 51908568), the Natural Science Foundation of Guangdong Province (2019A1515011981), the Natural Science Foundation of Beijing (Nos. 8204058 and 2184118), and the State Key Laboratory Open fund of Marine Resource Utilization in the South China Sea (Hainan University) (201904). 


\section{References}

[1] T. Honorio, B. Bary, and F. Benboudjema, "Thermal properties of cement-based materials: multiscale estimations at early-age," Cement and Concrete Composites, vol. 87, pp. 205-219, 2018.

[2] J. Kim, Y. C. Choi, and S. Choi, "Fractal characteristics of pore structures in GGBFS-based cement pastes," Applied Surface Science.vol. 428, pp. 304-314, 2017.

[3] Q. H. Nguyen, S. Lorente, and A. Duhard-Barone, "Effect of the pore size of cement based materials on ionic transport," Construction and Building Materials, vol. 147, pp. 160-167, 2017.

[4] P. K. Mehta and P. J. M. Monteiro, Concrete: Microstructure, Properties, and Materials, America, McGraw-Hill Company, Inc., New York, NY, USA, 2006.

[5] T. Zhang, Q. Yu, J. Wei, and P. Zhang, "A new gap-graded particle size distribution and resulting consequences on properties of blended cement," Cement and Concrete Composites, vol. 33, no. 5, pp. 543-550, 2011.

[6] X. Lu, S. X. Wang, C. H. Li, Z. M. Ye, and X. Cheng, "Properties and the hydration of portland limestone cement with diethanol-isopropanolamine," Ceramics-Silikáty, vol. 62, pp. 233-239, 2018.

[7] J. H. Zhao, L. Y. Tong, B. E. Li et al., "Eco-friendly geopolymer materials: a review of performance improvement, potential application and sustainability assessment," Journal of Cleaner Production, vol. 307, Article ID 127085, 2021.

[8] Á. Fernández, J. L. García Calvo, and M. C. Alonso, "Ordinary portland cement composition of ternary for the optimization of the synergies of supplementary cementitious materials binders in hydration processes," Cement and Concrete Composites, vol. 89, pp. 238-250, 2018.

[9] M. Heikal and H. El-Didamony, "Hydration and properties of blended cement systems incorporating industrial wastes," Ceramics-Silikáty, vol. 57, pp. 73-75, 2013.

[10] A. Aghaeipour and M. Madhkhan, "Effect of ground granulated blast furnace slag (GGBFS) on RCCP durability," Construction and Building Materials, vol. 141, pp. 533-541, 2017.

[11] Y. J. Zhang, Study on the theory and method of optimization design of mineral admixtures, Ph.D. thesis, Tongji University, Shanghai, China, 2004.

[12] C. Y. Lee, H. K. Lee, and K. M. Lee, "Strength and microstructural characteristics of chemically activated fly ash-cement systems," Cement and Concrete Research, vol. 33, no. 3, pp. 425-431, 2003.

[13] Y. Peng, S. Hu, and Q. Ding, "Dense packing properties of mineral admixtures in cementitious material," Particuology, vol. 7, no. 5, pp. 399-402, 2009.

[14] V. M. John, B. L. Damineli, M. Quattrone, and R. G. Pileggi, "Fillers in cementitious materials," Cement and Concrete Research, vol. 114, pp. 65-78, 2018.

[15] M. Záleská, M. Pavlíková, Z. Pavlík et al., "Physical and chemical characterization of technogenic pozzolans for the application in blended cements," Construction and Building Materials, vol. 160, pp. 106-116, 2018.

[16] I. Mehdipour and K. H. Khayat, "Understanding the role of particle packing characteristics in rheo-physical properties of cementitious suspensions: a literature review," Construction and Building Materials, vol. 161, pp. 340-353, 2018.

[17] J. Zhao, D. Wang, P. Yan, S. Zhao, and D. Zhang, "Particle characteristics and hydration activity of ground granulated blast furnace slag powder containing industrial crude glycerol-based grinding aids," Construction and Building Materials, vol. 104, pp. 134-141, 2016.

[18] J. Zhao, D. Wang, and P. Yan, "Design and experimental study of a ternary blended cement containing high volume steel slag and blast-furnace slag based on Fuller distribution model," Construction and Building Materials, vol. 140, pp. 248-256, 2017.

[19] K. E. Hassan, J. G. Cabrera, and R. S. Maliehe, "The effect of mineral admixtures on the properties of high-performance concrete," Cement and Concrete Composites, vol. 22, no. 4, pp. 267-271, 2000.

[20] J. J. Brooks, M. A. Megat Johari, and M. Mazloom, "Effect of admixtures on the setting times of high-strength concrete," Cement and Concrete Composites, vol. 22, no. 4, pp. 293-301, 2000.

[21] M. Uysal and K. Yilmaz, "Effect of mineral admixtures on properties of self-compacting concrete," Cement and Concrete Composites, vol. 33, no. 7, pp. 771-776, 2011.

[22] Y. Jiang, T. Ling, C. Shi, and S. Pan, "Characteristics of steel slags and their use in cement and concrete-a review," Resources, Conservation and Recycling, vol. 136, pp. 187-197, 2018.

[23] J. Zhao, P. Yan, and D. Wang, "Research on mineral characteristics of converter steel slag and its comprehensive utilization of internal and external recycle," Journal of Cleaner Production, vol. 156, pp. 50-61, 2017.

[24] J. Rosales, M. Cabrera, and F. Agrela, "Effect of stainless steel slag waste as a replacement for cement in mortars. Mechanical and statistical study," Construction and Building Materials, vol. 142, pp. 444-458, 2017.

[25] J. Zhao, D. Wang, P. Yan, D. Zhang, and H. Wang, "Selfcementitious property of steel slag powder blended with gypsum," Construction and Building Materials, vol. 113, pp. 835-842, 2016.

[26] J. Li, Q. Yu, J. Wei, and T. Zhang, "Structural characteristics and hydration kinetics of modified steel slag," Cement and Concrete Research, vol. 41, no. 3, pp. 324-329, 2011.

[27] M. X. Shi, Q. Wang, and Z. K. Zhou, "Comparison of the properties between high-volume fly ash concrete and highvolume steel slag concrete under temperature matching curing condition," Construction and Building Materials, vol. 98, pp. 649-655, 2015.

[28] J. Du and J. X. Liu, "Hydraulic properties and paste structure of basic oxygen furnace steel slag-cement blended materials," Fresenius Environmental Bulletin, vol. 22, pp. 3279-3286, 2013.

[29] B. Zhang, J. Hu, and M. Y. Li, "Hydration properties of steel slag under different curing temperatures," Applied Mechanics and Materials, vol. 507, pp. 295-299, 2014.

[30] Q. Wang, P. Yan, and J. Feng, "A discussion on improving hydration activity of steel slag by altering its mineral compositions," Journal of Hazardous Materials, vol. 186, no. 2-3, pp. 1070-1075, 2011.

[31] Y. M. Zhang, W. Sun, and H. D. Yan, "Hydration of highvolume fly ash cement pastes," Cement and Concrete Composites, vol. 22, no. 6, pp. 445-452, 2000. 